\title{
Either side of the door
}

I hear their footsteps outside the door They shout, loudly, I cant take anymore 'It's the police, we have a warrant' My bodies numb; thoughts incoherent

I panic; they want to take me away Are they deaf? they hear NOTHING I say Cursing, shouting, I scream unclearly! Holding the door-I cling to life dearly

"***** Off this is my house, my front door" Within a second I am thrown to the floor They bind me in cuffs; I am pinned to the ground I shout loudly, drowning out background sound

Forced out the door, I try to kick out They tie my legs; I scream loudly, swear, shout Tearing me away from my home, my freedom There it awaits; I have lost; I am beaten...
A locksmith, five in blue, four of us Beaten in number, sanity and force Atmosphere awkward; breathing tense We are here for their best interest?

We wait behind the door patient, poised emotion clouded by background noise all sounds drown out my inside thoughts Shouts resonate: "Stop I cant take anymore"

The door is broken, they run inside They launch, pin, pull them outside The assessment is brief but this they find No one's safe, in this state of mind

Relentless, screams spread so paranoid Attempting to avoid the inevitable: An admission,

But in this mental state theres no joint decision

Strangers stare, confused, full of fear Blue lights, sirens pierce both ears

It speeds, steady, loud down the street,

I stop, breathe, he is safe

Relief.

\section{Cliffe}

Correspondence to C Cliffe, Junior doctor and MA student, Dickson Poon Law School, Kings College London, London, UK; Charlotte.cliffe@nhs.net

Competing interests None.

Provenance and peer review Not commissioned; internally peer reviewed.

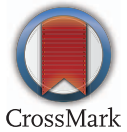

To cite Cliffe C. Med Humanit 2017:43:137.

Published Online First 1 December 2016

Med Humanit 2017;43:137. doi:10.1136/medhum-2016-011119 